\title{
Images of the month 2: Electrocardiographic QRS alternans caused by gastric volvulus
}

\author{
Authors: Éamon P McCarron, ${ }^{A}$ Monica Monaghan ${ }^{B}$ and Shiva Sreenivasan ${ }^{C}$
}

QRS electrical alternans is characterised by alternating amplitude of the QRS complexes, and is well-documented in cardiac conditions such as pericardial effusion. We describe a case of QRS alternans in a patient with gastric volvulus.

KEYWORDS: QRS alternans, gastric volvulus

\section{Introduction}

QRS electrical alternans is an electrocardiographic phenomenon defined as alternating amplitude or axis of the QRS complexes in any or all leads. It is well-documented in cardiac conditions such as pericardial effusion. ${ }^{1}$ We report a case of QRS alternans in a patient with gastric volvulus.

\section{Case presentation}

An 80-year-old woman presented to the emergency department with a 3-day history of persistent epigastric pain and vomiting. She was noted on clinical examination to have a regular tachycardia and marked parasternal heave. 12-lead electrocardiography (ECG) showed sinus tachycardia and QRS alternans (Fig 1). Plain chest radiography showed enlargement of a longstanding hiatal hernia (Fig 2), and subsequent contrast-enhanced computed tomography of the chest (Figs 3 and 4) demonstrated an intrathoracic, distended, obstructed stomach with marked anterior cardiac displacement and compression. Nasogastric tube (NGT) insertion attempts were unsuccessful. Stomach decompression was performed via oesophagogastroduodenoscopy, followed by gastropexy and percutaneous endoscopic gastrostomy insertion. She was discharged from hospital 4 weeks later and remains well.

\section{Discussion}

Gastric volvulus is often accompanied by a triad of symptoms described by Borchardt in 1904. ${ }^{1}$ This includes epigastric pain, excessive retching without vomiting, and inability to pass an NGT.

Authors: A specialty doctor in cardiology, South West Acute Hospital, Enniskillen, UK; ${ }^{B}$ consultant cardiologist, South West Acute Hospital, Enniskillen, UK; ${ }^{C}$ consultant in acute and internal medicine, South West Acute Hospital, Enniskillen, UK and School of Medicine, Dentistry, and Biomedical Sciences, Belfast, UK

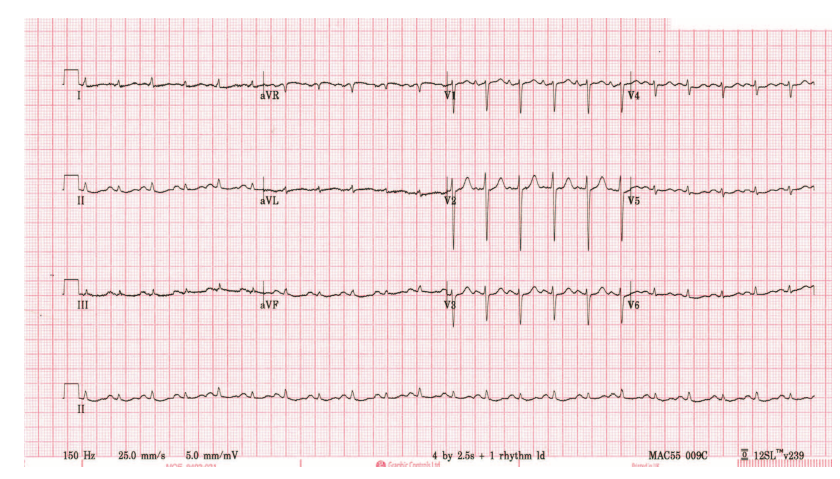

Fig 1. 12-lead electrocardiography showing sinus tachycardia with QRS alternans.

The condition carries a high mortality. ${ }^{2}$ There are well-documented cases of both cardiac and pulmonary causes of QRS alternans. ${ }^{3-5}$ This, however, appears to be the first reported case caused by gastric volvulus. We postulate that QRS alternans in this case was caused by pivoting of the compressed heart against the fulcrum of a tense, fluid-filled stomach (see Fig 5).

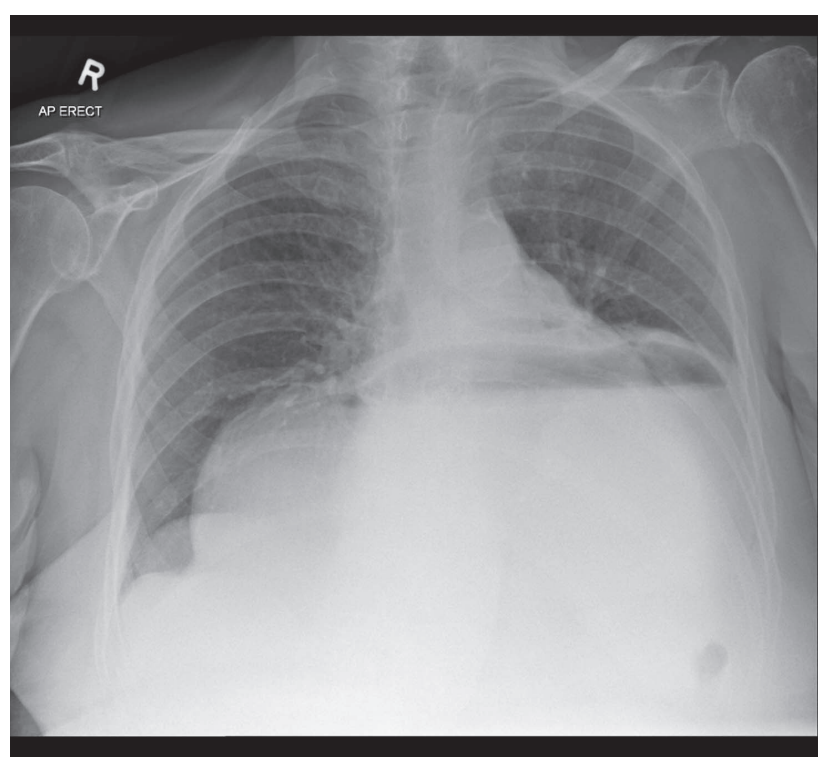

Fig 2. Chest radiography showing massive hiatal hernia. 

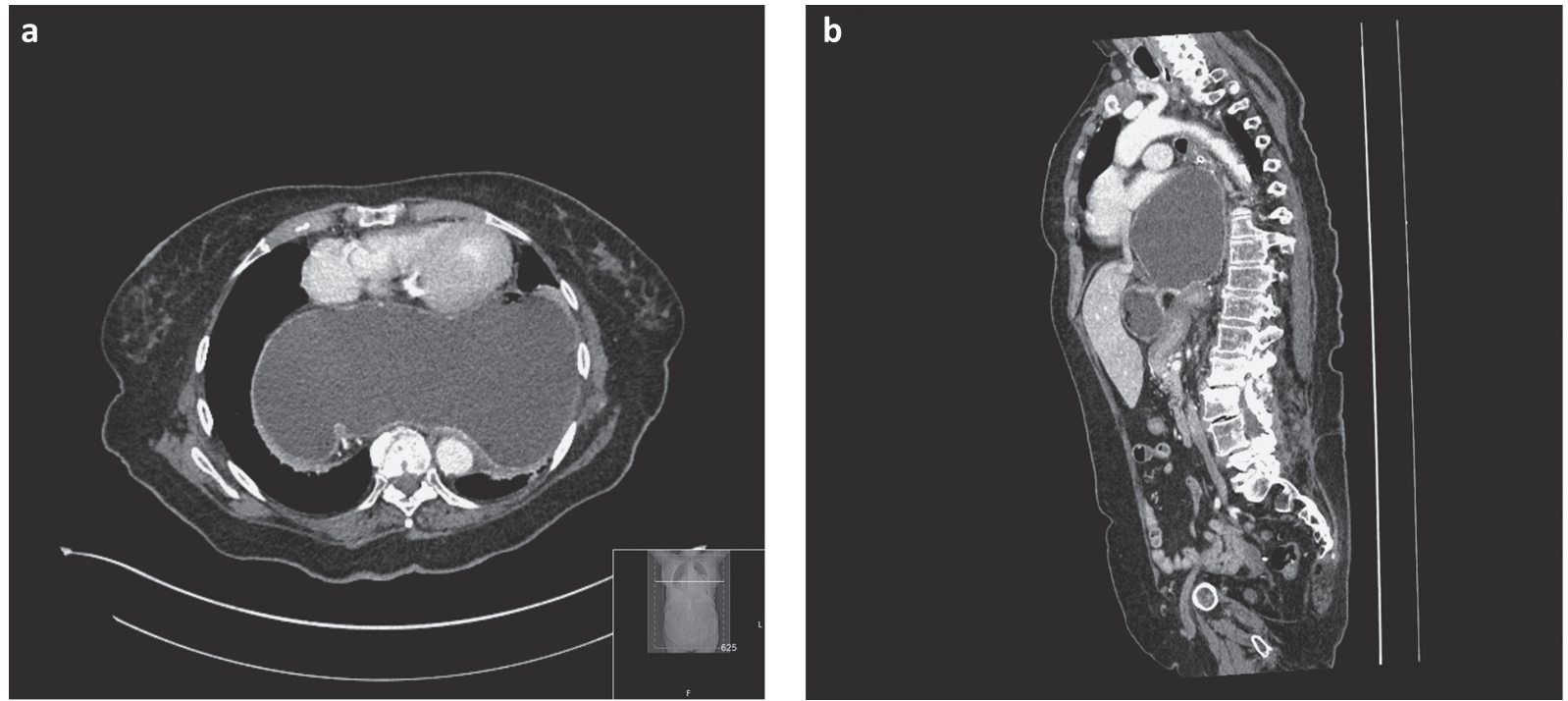

Fig 3. a) Axial computed tomography showing marked anterior cardiac displacement. b) Saggital image.
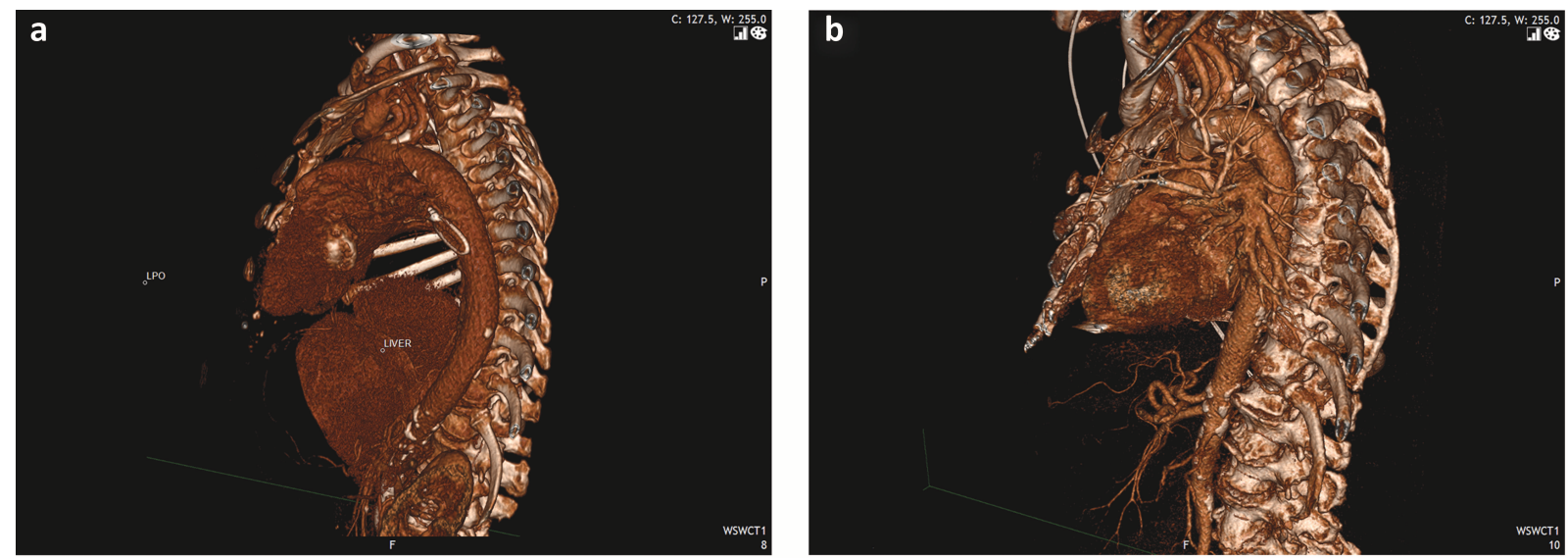

Fig 4. a) Left posterior oblique view of 3D volumetric reconstruction computed tomography showing degree of anterior cardiac compression. b) Similar view in normal patient for comparison.

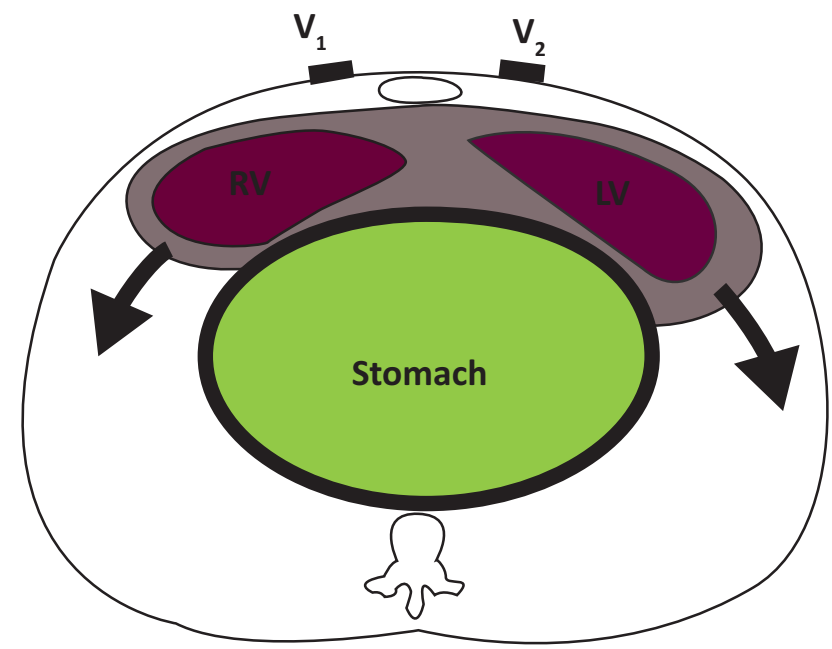

Fig 5. Proposed mechanism of QRS alternans in gastric volvulus.

\section{References}

1 Borchardt M. Zun pathologie und therapie des magnevolvulus. Arch Klin Chir 1904;74:243-60.

2 Teague WJ, Ackroyd R, Watson DI, Devitt PG. Changing patterns in the management of gastric volvulus over 14 years. Br J Surg 2000;87:358-61.

3 Niarchos AP. Electrical alternans in cardiac tamponade. Thorax 1975;30:228-33.

4 Hallengren B. Phasic voltage alternation in spontaneous left-sided pneumothorax. Acta Med Scand 1979;205:143-4.

5 Kounis NG, Mallioris CN, Karavias D, Zavras G, Siablis D. Unusual electrocardiographic changes in intrathoracic conditions. Acta Cardiol 1987:42:179-85.

Address for correspondence: Dr Shiva Sreenivasan, South West Acute Hospital, Western Health and Social Care Trust, Enniskillen BT74 6DN, UK.

Email: s.sreenivasan@qub.ac.uk 